\title{
Erforschungen der chemischen Zusammensetzung des Kulturträuschlings (Stropharia rugosa-annulata Farlow ex Murr.)
}

\author{
JORDAN S. KOSTADINOV und SPAS L. STEFANOV
}

\begin{abstract}
KOSTADINOV, J. S. \& STEFANOV, S. L. 1978: Erforschungen der chemischen Zusammensetzung des Kulturträuschilings (Stropharía rugoso-annulata Farlow ex Murr). - Karstenia 18 (suppl.).

Man hat eine chemische Analyse des Trauschlings in drei Reifengraden gemacht. Es wurden der Rohproteingehalt, reines Eiweiss, gesamte Kohlehydrate, Fasern, Lipide, Asche und Aminosarurenzusammensetzung bestimmt. Im alter des Fruchtkbrpers wird der Gehalt, von Eiweiss, Fasern und Asche kleiner und die Menge der Kohlenhydrate grosser. Fur die Konsomation sind die Fruchtkorper bis Reifengrad "halbgeschlossenem Hut" am geeignetsten.

J. S. Kostadinov, Experimental Station of Horticulture and Floriculture, Negovan, Sofia,

Bulgaria.
\end{abstract}

\section{Einleitung}

In den letzten Jahren wird der Kulturträuschling in vielen Ländern (wie in der DDR, der BRD, Polen, der Tschechoslowakei, Rumänien u.a.) gezüchtet (Püschel 1970, Kostadinov 1974).

Die Erforschungen der Zusammensetzung des Pilzes sind gering und unvollständig. Zur vollständigeren Charakteristik der bei uns gezuchteten Pilze hat man Forschungen der chemischen Zusammensetzung durchgefuhrt. Man beobachtete auch die Verănderungen, die bei der Fruchtreife eintreten. Man suchte dabei den geeignetsten Zustand zur Konsumtion.

\section{Material and Methode}

Fruchtkörper in verschiedener Fruchtreife hatte man aus Treibhäusern gesammelt, wo der Kulturtrăuschling in der Frühling-Sommersaison 1976 auf Substrat aus Weizenstroh und Decke aus Torfmull gezulchtet wurde. Die Pilze wurden gereinigt, bei $60^{\circ} \mathrm{C}$ getrocknet und gemahlen. Man ermittelte: das Rohprotein (gesamter Stickstoff $\times$ 6.25) nach der Methode von Kjeldahl); das reine Eiweiss aud dem Unterschied von Rohprotein und nichteiweissstickstoffhaltigen Substanzen, die aus dem Stoff mit $10 \%:$ ger Trichloressigsăure extrahiert wurden; die gesamten Kohlehydrate nach der Methode von Schorl, nach der Hydrolyse mit $10 \%: g e r$ Salzsäure innerhalb 3 Stunden bei $100^{\circ} \mathrm{C}$; die Fasern nach der Methode von Küschner und Hanak, durch Messen der Probe mit einem Gemisch aus Salpetersâure, Essigsäure und Wasser im Verhältnis $8: 1: 2$ in 30 Minuten, durch Filtrieren Schottfilter G-3, Spulen und Trocknen des Restes; die Lipide durch Extrahieren mit Athylalkohol.

Die Aminosäurenmenge, ohne Tryptophan, wurde mit Hilfe von einem Aminoanalysator bestimmt, nach einer Hydrolyse der Eiweisse in dem stoff mit 6-N Lösung der Salzsäure bei $105^{\circ} \mathrm{C}$ innerhalb 24 Stunden. Das
Tryptophan wurde kolorimetrisch mit p-dimetyl-aminobenzaldehyd nach der Methode von Udenfried und Peterson (1957) bestimmt.

\section{Ergebnisse}

Die Ergebaisse der Forschungen ohne Aminosăurenzusammensetzung sind in der Tabelle 1 angegeben.

Aus dem Angaben in der Tabelle sieht man, dass mit der Reife der Fruchtkörper auch ihre Zusammensetzung sich veränderte. Die Menge des Rohproteins, respektive des reinen Eiweisses wird kleiner und die der Kohlehydrate wird jeweilig grösser, da die Synthese der Kohlehydrate mit der Reife der Fruchtkörper schneller vor sich geht, im Vergleich zu den stickstoffhaltigen Substanzen. Dieselbe Gesetzmassigkeit beobachtet man auch bei den Fasern und der Asche, deren Gehalt jeweilig kleiner wird. Der Lipidengehalt ist sehr gering und die Unterschiede bei den einzelnen Reifungsgraden sind unbeträchtlich.

Tabelle 1. Chemische Analyse von Fruchtkörpern des Kulturträuschlings in verschiedener Reifungsgraden (\% zu absoluter Trockensubstanz).

\begin{tabular}{lccc}
\hline Inhaltsstofe & \multicolumn{3}{c}{ Reifungsgrad } \\
\cline { 2 - 4 } & $\begin{array}{c}\text { Geschlossener } \\
\text { Pilz }\end{array}$ & $\begin{array}{c}\text { Halbgeschlossener } \\
\text { Pilz }\end{array}$ & $\begin{array}{c}\text { Flacher } \\
\text { Pilz }\end{array}$ \\
\hline Rohprotein & 31.9 & 27.3 & 20.6 \\
Reineiweiss & 21.6 & 18.4 & 13.1 \\
Kohlehydrate im & & & \\
allgemeinen ohne & 35.3 & 40.2 & 49.3 \\
Zellstoff & 8.7 & 7.3 & 5.7 \\
Fasern & 8.5 & 7.9 & 7.2 \\
Asche & 1.4 & 1.1 & 1.2 \\
Lipide & & & \\
\end{tabular}


Tabelle 2. Zusammensetzung der Aminosäuren in den Fruchtkörpern des Kulturtrăuschlings im Zusammenhang mit dem Reifungsgrad.

\begin{tabular}{|c|c|c|c|c|c|c|}
\hline \multirow{3}{*}{ Aminosäure } & \multicolumn{6}{|c|}{ Reifungsgrad } \\
\hline & \multirow{2}{*}{$\begin{array}{l}\text { Geschlossener } \\
\% \text { zur abso- } \\
\text { luten } \\
\text { Trocken- } \\
\text { substanz }\end{array}$} & \multirow{2}{*}{$\begin{array}{l}\text { Pilz } \\
\% \text { von } \\
\text { der } \\
\text { Summe }\end{array}$} & \multicolumn{2}{|c|}{$\begin{array}{l}\text { Halbgeschlossener } \\
\text { Pilz }\end{array}$} & \multicolumn{2}{|c|}{ Flacher Pilz } \\
\hline & & & $\begin{array}{l}\text { \% zur abso- } \\
\text { soluten } \\
\text { Trocken- } \\
\text { substanz }\end{array}$ & $\begin{array}{l}\text { \% von } \\
\text { der } \\
\text { Summe }\end{array}$ & $\begin{array}{l}\text { \% zur abso- } \\
\text { soluten } \\
\text { Trocken- } \\
\text { substanz }\end{array}$ & $\begin{array}{l}\text { \% von } \\
\text { der } \\
\text { Summe }\end{array}$ \\
\hline \multicolumn{7}{|l|}{ A. Unersătzlich } \\
\hline Lysin & 1.10 & 5.77 & 1.09 & 7.09 & 0.81 & 6.85 \\
\hline Threonin & 1.13 & 5.93 & 0.85 & 5.53 & 0.68 & 5.75 \\
\hline Valin & 1.19 & 6.25 & 0.88 & 5.73 & 0.62 & 5.24 \\
\hline Methionin & 0.18 & 0.94 & 0.26 & 1.69 & 0.20 & 1.69 \\
\hline Ieuzin & 1.72 & 9.03 & 1.10 & 7.16 & 0.85 & 7.19 \\
\hline Isoleuzin & 0.81 & 4.25 & 0.60 & 3.90 & 0.45 & 3.80 \\
\hline Phenylalanin & 0.87 & 4.57 & 0.54 & 3.51 & 0.43 & 3.63 \\
\hline Tryptophan & 0.37 & 1.94 & 0.32 & 2.08 & 0.24 & 2.03 \\
\hline \multicolumn{7}{|l|}{ B. Ersătzlich } \\
\hline Histidin & 0.39 & 2.05 & 0.43 & 2.80 & 0.31 & 2.62 \\
\hline Arginin & 0.97 & 5.09 & 0.94 & 6.12 & 0.65 & 5.49 \\
\hline Asparaginsăure & 2.24 & 11.76 & 1.80 & 11.71 & 1.40 & 11.83 \\
\hline Serin & 1.14 & 5.98 & 0.88 & 5.73 & 0.68 & 5.75 \\
\hline Glutaminsäure & 3.26 & 17.11 & 2.58 & 16.79 & 2.14 & 18.09 \\
\hline Prolin & 0.64 & 3.36 & 0.95 & 6.18 & 0.68 & 5.75 \\
\hline Glycin & 0.96 & 5.04 & 0.70 & 4.55 & 0.55 & 4.65 \\
\hline Alanin & 1.29 & 6.77 & 1.06 & 6.90 & 0.83 & 7.02 \\
\hline Cystein & 0.09 & 0.47 & - & - & - & - \\
\hline Tyrosin & 0.70 & 3.67 & 0.39 & 2.57 & 0.31 & 2.62 \\
\hline
\end{tabular}

In der Tabelle 2 ist die Aminosäurenzusammensetzung des Pilzes in \% in Bezug auf das absolut trockene Produkt und aus der summe der bestimmten Aminosäuren angegeben.

Aus der Tabelle geht hervor, dass mit dem Reifen des Fruchtkörpers die Menge der Aminosăuren kleiner wird.

\section{Schlussfolgerung}

Der Kulturträuschling ist von Interesse nicht nur durch seine Geschmackeigenschaften, sondern auch durch seine chemische Zusammensetzung. Er gehört zu den an Protein mittelreichen Pilzen. Bei den Versuchen betrug die Rohproteinmenge, abhängig vom Reifungsgrad des Fruchtkörpers, 20.6-31.9\%. Nach Lelley (1976) enthäl der Trăuschling $11 \%$ Rohprotein. Das Verhältnis des reinen Eiweisses zum Rohprotein bei den ersten zwei Reifungsgraden war $67.7 \%$ und $67.4 \%$. Bei den flachen Pilzen war es etwas niedriger als $63.6 \%$, denn bei ihnen wurde die Menge der nichteiweissstickst of fhaltigen substanzen grösser.
Beim Forschreiten der Reife des Fruchtkörpers, tratsen Veränderungen im Verhăltnis zwischen den einzelnen Aminosäuren ein.

Die unersetzlichen Aminosäuren im Eiweiss des Träuschlings sind gut balanciert mit Ausnahme des Methionins. Characteristisch für den Pilz ist der verhaltnismässig hohe Gehalt an Tryptophan.

Wenn wir voin dem Proteingehalt und der Aminosăurenzusammensetzung ausgehen, sind wir der Meinung, dass fur die Konsumtion die geschlossenen und halbgeschlossenen Pilze die geeignetsten sind.

\section{Literatur}

Kostadinov, J.S. 1974: - Z. Sp. Gradinarstvo 10: 38-40.

Lelley, J. 1976: - Anregung für Produktion und Absatz 9: 7 .

Püschel, I. 1970: - Mycologisches Mitteilungblatt 14: 17-22.

Udenfried, S. \& Peterson, A.E. 1957: - Methods in Enzymology 3: 613. 